\title{
PENGEMBANGAN MEDIA INFORMASI UNTUK PELAYANAN PENDAFTARAN PASIEN DI BPM RIKA HARDI, S.ST
}

\section{MEDIA INFORMATION DEVELOPMENT FOR PATIENT REGISTRATION SERVICE IN BPM RIKA HARDI, S.ST}

\author{
Rahmi Septia Sari* \\ Program Studi Ilmu Rekam Medis, Apikes Iris \\ Email: rahmiseptiasari88@gmail.com
}

\begin{abstract}
ABSTRAK
Fasilitas kesehatan merupakan pelayanan yang sangat penting bagi masyarakat. Pelayanan kesehatan adalah tulang punggung fasilitas kesehatan di Indonesia. Fasilitas kesehatan bisa dimiliki oleh Pemerintah, Pemerintah Daerah atau swasta. Tenaga kesehatan terdiri dari beragam profesi seperti tenaga dokter, bidan, perawat, apoteker, ahli gizi, tenaga perekam medis, tenaga manajemen kesehatan maupun tenaga non kesehatan. Pasien yang datang ke fasilitas kesehatan pun memiliki beragam jenis penyakit mulai dari penyakit menular sampai penyakit degeneratif. Oleh karena itu, dalam hal ini dilakukan penyusun alur dan prosedur pendaftaran pasien sehingga pelayanan berlangsung baik. Salah satu kriteria penilaian akreditasi pada suatu fasilitas kesehatan adalah tersedianya informasi tentang alur prosedur pendaftaran pelayanan saat pasien mendaftar di loket pendaftaran. Kejelasan informasi yang diterima pasien akan memberikan rasa puas terhadap pasien. Kesan pertama di loket pendaftaran akan membentuk persepsi pasien terhadap keseluruhan pelayanan di fasilitas kesehatan. Tujuan kegiatan ini menyediakan media informasi untuk edukasi pasien saat mendaftar tentang alur dan prosedur pelayanan di loket pendaftaran. Metode yang lakukan adalah observasi ke fasilitas pelayanan kesehatan, identifikasi dan analisis kebutuhan media informasi, perencangan media informasi, ujicoba media, sosialisasi, dan evaluasi. Hasil yang diperoleh tersedianya media informasi dalam bentuk banner tentang alur prosedur pelayanan di fasilitas kesehatan.
\end{abstract}

Kata Kunci: Media, Alur prosedur pendaftaran, Bidan praktek mandiri

\section{ABSTRACT}

Health facilities are very important services for the community. Health services are the backbone of health facilities in Indonesia. Health facilities can be owned by the Government, Local Government or private. Health workers consist of various professions such as doctors, midwives, nurses, pharmacists, nutritionists, medical record workers, health management personnel and non-health workers. Patients who come to health facilities also have a variety of diseases ranging from infectious diseases to degenerative diseases. Therefore, here I am trying to develop a flow and procedure for patient registration. One of the criteria for evaluating accreditation at a health facility is the availability of information about the flow of the procedure for registering services when patients register at the registration counter. Clarity of information received by the patient will give satisfaction to the patient. First impressions at the registration window will shape the patient's perception of the overall service in the health facility. The purpose of this activity is to provide information media for patient education when registering the flow and procedure of service at the registration counter. The method used is observation to health care facilities, identification and analysis of media information needs, information media planning, media testing, outreach, and evaluation. The results obtained are the availability of information media in the form of banners about the flow of service procedures in health facilities.

Keywords: Media, Registration procedure flow, Midwife independent practice

\section{PENDAHULUAN}

Instansi kesehatan yang memberikan

pelayanan optimal dapat memberikan kepuasan dan kepercayaan pasien untuk berobat. Dengan

adanya perbaikan sistempelayanan, diharapkan

mampu memenuhi strategi untuk bersaing 
dalam pelayanan kesehatan. Perbaikan sistem dapat diwujudkan dalam bentuk sistem informasi rekam medis. Menurut Rano (2017) sarana pelayanan kesehatan wajib membuat dan merawat rekam medis dari setiap pasien yang dilayaninya. Rekam medis adalah berkas yang berisi catatan dan dokumen tentang identitas pasien, pemeriksaan pengobatan, tindakan dan pelayanan lain yang telah diberikan suatu instansi kesehatan. Salah satu Pelayanan Kesehatan Bidan Praktek Mandiri [1].

Menurut KEMENKES RI No: 128/MENKES/SK/II/2004 untuk mencapai tujuan pembangunan kesehatan diselenggarakan berbagai upaya kesehatan secara menyeluruh, berjenjang dan terpadu. Puskesmas adalah penanggungjawab penyelenggara upaya kesehatan untuk jenjang tingkat pertama.Pemeliharaan dan pengambilan data Rekam Medis merupakan fungsi penting setiap fasilitas asuhan kesehatan. Dua alat yang dipakai untuk memudahkan pemeliharaan dan pengambilan informasi kesehatan ini adalah indeks dan register. yang berfungsi untuk mengarahkan, menunjukkan, atau memudahkan rujukan. Register adalah "Catatan resmi berbagai hal, nama, atau tindakan.hampir semua indeks dan register fasilitas asuhan kesehatan dikumpul secara manual. Jenis informasi tertentu mengenai pasien dan asuhan pasien diinformasikan dari catatan medis dan ditempelkan pada lembaran kartu-kartu.

Fasilitas Kesehatan merupakan garda depan dalam penyelenggaraan upaya kesehatan dasar. Suatu fasilitas kesehatan dapat menjalankan fungsinya secara optimal, maka harus dikelola secara optimal baik kinerja pelayanan, proses pelayanan, maupun sumber daya yang digunakan. Masyarakat menghendaki pelayanan kesehatan yang aman dan bermutu, serta dapat menjawab kebutuhan mereka, oleh karena itu upaya peningkatan mutu, manajemen risiko dan keselamatan pasien perlu diterapkan dalam pengelolaan Pelayanan kesehatan antara lain fasilitas Bidan Praktek Mandiri. Untuk menjamin bahwa perbaikan mutu, peningkatan kinerja dan penerapan manajemen risiko dilaksanakan secara berkesinambungan di fasilitas kesehatan, maka perlu dilakukan penilaian oleh pihak eksternal dengan menggunakan standar yang ditetapkan yaitu melalui mekanisme akreditasi [2].

Prinsip dari pelayanan kesehatan yang bermutu adalah keberpihakan terhadap pelanggan. Dua hal yang perlu dipantau dalam upaya perbaikan mutu adalah kepuasan pelanggan dan standar pelayanan kesehatan yang harus dilakukan secara seimbang [3]. Fasilitas wajib menyediakan informasi tentang pelayanan kesehatan yang diberikan kepada masyarakat sebagai wujud dari hak akses masyarakat terhadap pelayanan kesehatan. Keselamatan pasien sudah harus diperhatikan sejak pertama pasien kontak dengan fasilitas kesehatan, dengan demikian prosedur pendaftaran sudah mencerminkan penerapan upaya keselamatan pasien, terutama dalam identifikasi pasien.

Pasien membutuhkan informasi yang jelas di tempat pendaftaran, oleh karena itu informasi pendaftaran harus tersedia dengan jelas yang dapat dengan mudah diakses dan dipahami oleh 
pasien. Pasien mempunyai hak untuk staf medis penanggung jawab unit pelayanan, memperoleh informasi tentang tahapan nomor pasien, alamat lengkap, tempat/tanggal pelayanan klinis yang akan dilalui mulai dari lahir, umur, jenis kelamin, status keluarga, proses kajian sampai pemulangan. Informasi agama dan pekerjaan. Pentingnya informasi tentang tahapan pelayanan yang ada di informasi tersebut menjadi dasar utama Puskesmas perlu diinformasikan kepada pasien untuk menjamin kesinambungan pelayanan. Informasi tersebut termasuk apabila pasien perlu dirujuk ke fasilitas yang lebih tinggi dalam upaya menjamin kesinambungan pelayanan. Tahapan pelayanan klinis adalah tahapan pelayanan sejak mendaftar, diperiksa sampai dengan meninggalkan tempat pelayanan dan tindak lanjut di rumah jika diperlukan [2].

Menurut Kotler (1994), definisi kepuasan konsumen adalah tingkat perasaan seseorang setelah membandingkan kinerja/hasil yang dirasakan dibandingkan dengan harapannya. Jika persepsi konsumen terhadap suatu produk atau jasa melebihi apa yang diharapkan, tentu saja konsumen sangat puas, akan tetapi jika persepsi konsumen berada di bawah tingkat yang diharapkan, tentu saja konsumen tidak puas atau sangat kecewa [4].

Agar informasi tersampaikan dengan baik kepada sasaran diperlukan saluran berupa media yang tepat [5]. Salah satu media yang digunakan dalam proses pembelajaran dan diyakini dapat lebih menggairahkan adalah media visual. Media visual adalah media penyampai informasi yang memiliki karakteristik visual. Jenis media ini memiliki kemampuan lebih baik karena memiliki karakteristik visual yang jelas [6].

Pedoman Penyelenggaraan Rekam Medis terdapat beberapa informasi penting yang harus ditangkap oleh petugas pendaftaran, antara lain:

pengumpulan data dan informasi pasien yang terpenting sebelum pelayanan dilaksanakan. Media sebagai salah satu upaya edukasi bagi pasien maupun keluarganya untuk memperoleh informasi serta tujuan dari lengkapnya data pasien [1].

\section{METODE PELAKSANAAN KEGIATAN}

Metode dalam pelaksanaan kegiatan ini berupa identifikasi dan diskusi melalui wawancara. Adapun tahapan kegiatan yang dilakukan antara lain:

1. Observasi kepada pihak fasilitas Bidan Praktek Mandiri (BPM) Rika Hardi, S.ST. Sasaran dalam kegiatan ini adalah pimpinan BPM, petugas rekam medis dan petugas pada setiap unit pelayanan yang ada di BPM yaitu unit pemeriksaan umum, pelayanan KIA/KB . Kegiatan ini ditujukan untuk mendapatkan dukungan dalam pelaksanaan kegiatan.

2. Identifikasi kebutuhan isi media informasi. Identifikasi kebutuhan isi media informasi alur dan prosedur pelayanan dilakukan dengan cara berdiskusi dengan pihak BPM Rika Hardi. Diskusi tersebut antara lain membahas mengenai media informasi yang sudah tersedia

3. Merancang Media Informasi. Media informasi yang dirancang adalah dalam bentuk banner tentang alur pelayanan perndaftaran pasien. 
4. Sosialisasi. Media yang sudah tersusun dilakukan kepada seluruh petugas BPM Rika Hardi, S.ST. Setelah disepakati oleh seluruh petugas fasilitas, selanjutnya media hasil pengembangan disosialisasikan kepada pasien BPM Rika Hardi, S.ST.

5. Evaluasi. Media informasi yang sudah selesai dibuat dipromosikan pada saat pelayanan pendaftaran di BPM Rika Hardi, S.ST. Evaluasi dilakukan dengan cara diskusi dengan pihak fasilitas untuk pemasangan media agar terintegrasi dalam program pelayanan pendaftaran.

\section{HASIL DAN PEMBAHASAN}

Hasil dari kegiatan berupa tersedianya media informasi untuk edukasi pasien dalam pelayanan pendaftaran berupa alur dan prosedur pelayanan di BPM Rika Hardi, S.ST. Sebagaimana dinyatakan dalam standar akreditasi fasilitas pelayanan keehatan bahwa informasi tentang pelayanan wajib disediakan oleh Fasilitas kesehatan sebagai bentuk pemenuhan hak pasien mendapatkan informasi yang jelas dan akurat. Selain itu juga dalam presfektif mutu khususnya dimensi jaminan dinyatakan bahwa konsumen akan mempersepsikan rasa puas terhadap pelayanan apabila ada jaminan kejelasan apa yang akan dilalui dan didapatkan selama mendapat pelayanan.

Media informasi yang dibuat adalah tentang alur pendaftaran pasien. Dalam media informasi tersebut digambarkan pertama kali adalah kondisi pasien dating ke fasilitas. Apabila kondisi pasien gawat maka langsung menuju ruang tindakan, namun apabila kondisi pasien tidak gawat darurat maka pasien mengambil nomor urut. Untuk nomor urut dibedakan menjadi 2 (dua) apakah pasien umum atau pasien BPJS. Setelah pasien mendapatkan nomor antrian selanjutnya menunggu di ruang tunggu. Pasien dipanggil oleh petugas pendaftaran sesuai dengan nomor antrian.

Pada saat dipanggil oleh petugas, pasien akan ditanyakan (a) Apakah sudah pernah berobat atau belum di BPM Rika Hardi, .ST (meminta Kartu Identitas Berobat); (b) Menunjukan kartu identitas diri; (c) Pasien ditanyaapakah memiliki kartu jeminan kesehatan; (d) Unit Pelayanan yang dituju (Kehamilan, Persalinan, KIA, Imunisasi dan $\mathrm{KB})$. Setelah itu petugas akan menyiapkan rekam medis sesuai dengan status pasien (baru atau lama), menulis identitas pasien kedalam buku register. Pasien selanjutnya menunggu di ruang tunggu unit pelayanan. Pasien selanjutnya dipanggil menuju ruang pemeriksaan. Setelah mendapat pelayanan di unit pelayanan yang dituju ada beberapa kemungkinan terhadap pasien antara lain: (a) Pasien dirujuk ke fasilitas pelayanan kesehatan lanjutan; (b) Pasien mendapat konseling; (c) Pasien mendapat resep obat; (d) Pasien memerlukan pemeriksaan penunjang lanjutan. Adapun hasil dari pengembangan media informasi tersebut berupa banner yang berisi tentang alur pendaftaran pasien sebagaimana terlihat pada Gambar 1. 


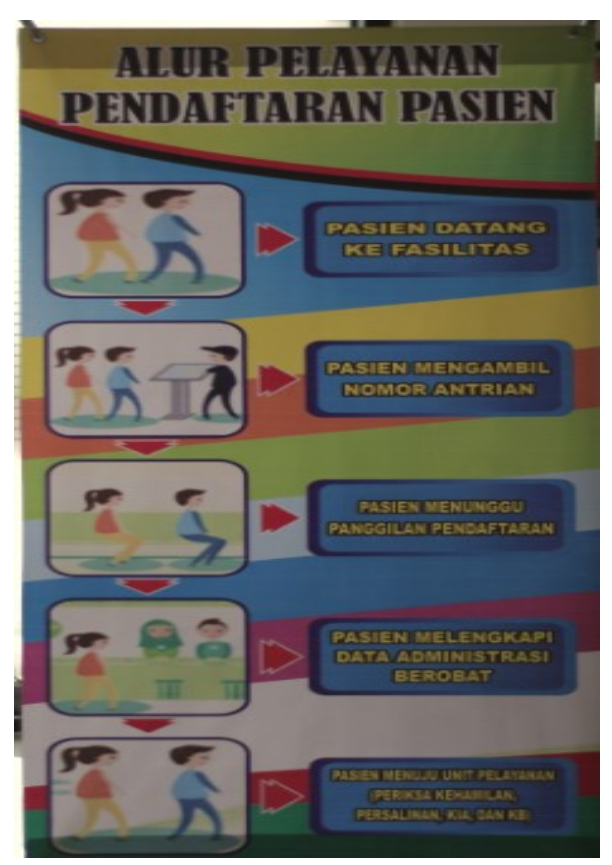

Gambar 1. Banner Alur Pendaftaran Pasien

Banner tersebut dipasang di pintu masuk Fasilitas BPM Rika Hardi, S.ST. Melalui informasi tersebut pasien sudah mendapatkan gambaran tahapan apa saja yang akan dialami pasien selama di fasilitas serta berkas apa saja yang harus disiapkan pasien untuk menunjang pelayanan di pendaftaran lebih cepat. Banner dipasang di posisi pintu masuk sehingga pada saat pasien masuk fasilitas sudah ada petunjuk untuk pendafran dalam mendapatkan pelayanan kesehatan.

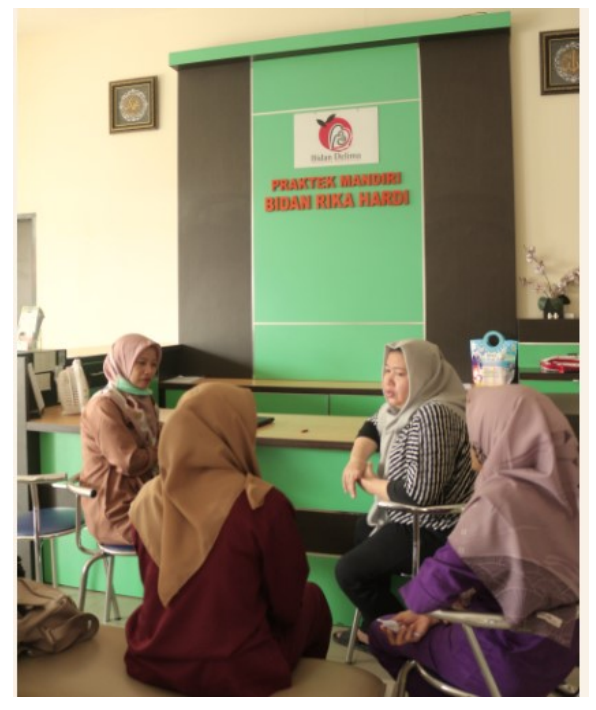

Gambar 2. Pemaparan materi secara langsung

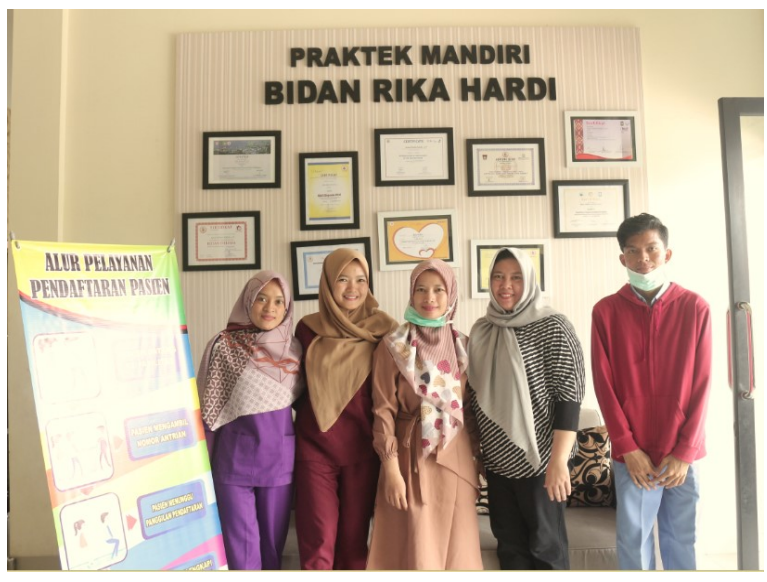

Gambar 3. Narasumber, pimpinan BPM dan perwakilan petugas rekam medis

\section{KESIMPULAN}

Persepsi pasien terhadap mutu pelayanan kesehatan di fasilitas pelayanan kesehatan BPM Rika Hardi,S.ST dapat dimulai dari kesan yang diperolehnya pada saat pelayanan pendaftaran. Informasi yang jelas dan akurat yang disediakan akan membantu pasien mendapatkan pelayanan yang cepat khususnya di pendaftaran. Oleh karena itu pembuatan Banner tentang alur dan prosedur pendaftaran pasien dapat mendorong memahami apa yang akan dilaluinya dalam menerima pelayanan di BPM Rika Hardi, S.ST.

\section{REFERENSI}

[1] Depkes RI, Pedoman Penyelenggaraan Rekam Medis Rumah Sakit di Indonesia. Jakarta: Depkes RI, 2006.

[2] Kementerian kesehatan RI. 2015. Peraturan Menteri Kesehatan Nomor 46 Tahun 2015 tentang Akreditasi Puskesmas, Klinik Pratama, Tempat Praktik Mandiri Dokter, dan Tempat Praktik Mandiri Dokter Gigi, Jakarta

[3] Rizanda Machmud. 2008. Manajemen Mutu Pelayanan Kesehatan. Jurnal Kesehatan Masyarakat Andalas, pp. 186 - 190

[4] Hisyam Hermawan, $M$ and Nuri Kartini. 2016. Analisa Kepuasan Pelayanan Kesehatan Dengan Pendekatan Importance Performance Analysis Dan Potential Gain In Customer Value's. Jurnal Improvement, 
pp. $31-39$

[5] Rudi Susilana and C Riyana. 2008. Pembelajaran: Hakikat, Pengembangan, Pemanfaatan, dan Penilaian. Wacana Prima
[6] Sapto Haryoko. 2009. Efektivitas Pemanfaatan Media Audio Visual Sebagai Alternatif Optimalisasi Model Pembelajaran. Jurnal Edukasi Elektro, 5(1):1-10 